\title{
Age-dependent effect of metabolic phenotypes on carotid atherosclerotic disease in coronary heart disease patients (CORDIOPREV study)
}

Francisco M. Gutierrez-Mariscal ${ }^{1,2}$ @D, Antonio García-Ríos ${ }^{1,2}$, Purificación Gómez-Luna ${ }^{1,2}$, Carolina Fernández-Gandara ${ }^{1,2}$, Magdalena P. Cardelo ${ }^{1,2}$, Silvia de la Cruz-Ares ${ }^{1,2}$ (D) Fernando Rodriguez-Cantalejo ${ }^{3}$, Raul M. Luque ${ }^{2,4}$, Ana León-Acuña 1,2, Javier Delgado-Lista,2, Pablo Perez-Martinez ${ }^{1,2}$,

Elena M. Yubero-Serrano ${ }^{1,2+}$ (D) and Jose Lopez-Miranda ${ }^{1,2^{*+}}$ (D)

\begin{abstract}
Background: Aging is associated with a high risk for cardiovascular disease. The relation of obesity and risk of cardiovascular events appears to be more closely linked to certain clinical or metabolic phenotypes than to obesity itself. Our aim was to establish whether aging influenced the metabolic phenotypes regarding to cardiovascular risk, evaluated by changes in the intima media thickness-common carotid (IMT-CC), in coronary heart disease (CHD) patients.
\end{abstract}

Methods: In this cross-sectional study, 1002 CHD patients were studied at entry from the CORDIOPREV study. We performed carotid ultrasound assessment to obtain their IMT-CC values. Carotid atherosclerosis was considered to exist if IMT-CC $>0.7 \mathrm{~mm}$.

Results: Age determined a higher IMT-CC, regardless metabolic phenotype (all $p<0.05$ ). Metabolically healthy nonobese (MHNO) aged $<60$ showed a lesser prevalence for carotid atherosclerotic disease than metabolically sick nonobese (MSNO) and obese (MSO), while MHNO aged $\geq 60$ only showed less prevalence for the disease than the MSO. Carotid atherosclerosis associated with age, sex, impaired fasting glucose (IFG), hypertension and high sensitivity Creactive protein (hsCRP). However, in patients aged $<60$, it associated with sex and IFG and in the age $\geq 60$ group, with hypertension and hsCRP.

(Continued on next page)

\footnotetext{
* Correspondence: jlopezmir@uco.es

${ }^{\dagger}$ Elena M. Yubero-Serrano and Jose Lopez-Miranda contributed equally to this work.

${ }^{1}$ Lipids and Atherosclerosis Research Unit, Avda. Menéndez Pidal, s/n, Reina Sofia University Hospital, Maimonides Institute for Biomedical Research in Cordoba (IMIBIC), University of Córdoba, 14004 Córdoba, Spain

${ }^{2}$ CIBER Physiopathology of Obesity and Nutrition (CIBEROBN), Carlos III Health Institute, Madrid, Spain

Full list of author information is available at the end of the article
}

(c) The Author(s). 2020 Open Access This article is licensed under a Creative Commons Attribution 4.0 International License, which permits use, sharing, adaptation, distribution and reproduction in any medium or format, as long as you give appropriate credit to the original author(s) and the source, provide a link to the Creative Commons licence, and indicate if changes were made. The images or other third party material in this article are included in the article's Creative Commons licence, unless indicated otherwise in a credit line to the material. If material is not included in the article's Creative Commons licence and your intended use is not permitted by statutory regulation or exceeds the permitted use, you will need to obtain permission directly from the copyright holder. To view a copy of this licence, visit http://creativecommons.org/licenses/by/4.0/ The Creative Commons Public Domain Dedication waiver (http://creativecommons.org/publicdomain/zero/1.0/) applies to the data made available in this article, unless otherwise stated in a credit line to the data. 


\begin{abstract}
(Continued from previous page)
Conclusions: Our results suggest that CHD patients aged $\geq 60$ are less metabolic flexible compared to patients aged $<60$. Thus, $\mathrm{MHO}$ patients aged $\geq 60$ show the same risk of suffering carotid atherosclerosis as those with metabolic disease, while MHO patients aged $<60$ show lower risk than MSO. This fact indicates the need to focus on therapeutic strategies in order to modify those parameters related to obesity and metabolic inflexibility in patients with CHD before entering old age.
\end{abstract}

Keywords: Metabolically healthy obese, Cardiovascular risk factors, Metabolic flexibility, Carotid atherosclerosis

\section{Background}

Aging can be defined as a natural process in which the chances of survival of an organism gradually decline. It is a multifactorial process involving genetic and environmental factors [22, 30]. Aging is associated with an increased risk of suffering age-related diseases such as diabetes, cancer, neurodegenerative diseases or dementia, and is also widely considered as a cardiovascular risk factor [25]. It is common knowledge that body weight tends to increase with age, except in the elderly, while the prevalence of metabolic disease is higher among older individuals, particularly those with obesity $[3,17]$.

Obesity, defined as abnormal or excessive body fat accumulation, is related to an increased risk of cardiometabolic diseases [21, 31]. Over the past decades, it has increased worldwide as is now considered a pandemic, not only in the middle-aged or pediatric population, but also in the elderly $[7,29]$. There is increasing evidence to suggest that not all individuals in obese populations display metabolic disorders and a high cardiovascular risk associated with obesity and, conversely, not all normal-weight individuals are in a favorable metabolic condition [10]. In fact, our current knowledge suggests that it is not obesity itself, but certain clinical or metabolic phenotypes associated with it, which are linked to an increase of the cardiovascular risk [12, 15, 28]. In this context, the so-called metabolically healthy obese phenotype is characterized by increased body fat and a favorable cardiovascular profile (high levels of HDLcholesterol, normal glucose and triglyceride levels and good insulin sensitivity) [11, 26]. However, normalweight individuals with metabolic disease show early signs of insulin resistance, hyperinsulinemia, atherogenic dyslipidemia and hypertension, with a high susceptibility to develop diabetes and cardiovascular disease (CVD) $[11,15]$. However, to date, it is not known whether the associated cardiovascular risk with metabolic phenotypes could be modified by age.

Taking all the above into account, the aim of the present study was to establish whether age influences the cardiovascular risk associated with metabolic phenotypes (the presence/or absence of obesity and/or metabolic disease), measured by intima-media thickness of both the common carotid arteries (IMT-CC), as marker of carotid atherosclerosis, in a large cohort of coronary heart disease (CHD) patients. The identification of these potential associations would provide evidence to allow the use of more intensive medical interventions and prevention strategies aimed at reducing CVD risk and delay an age-related decline in health.

\section{Methods \\ Population}

This work has been carried out in the setting of the CORDIOPREV study (Clinical Trials Registry NCT00924937). The study protocol was designed in accordance with the principles of the Declaration of Helsinki, approved by the Human Investigation Review Committee of the Reina Sofia University Hospital, and according to institutional and Good Clinical Practice guidelines. The CORDIOPREV study is described in depth in previously published report [6]. For the specific aim of this work, we performed a cross-sectional analysis of the CORDIOPREV population at baseline and the patients were classified according to: 1) Age, up and under the median of our studied population, 60 years; 2 ) the presence/or absence of obesity [body mass index (BMI) < 30 and $\geq 30$ ] and 3) metabolic disease (described below). From the initial sample of 1002 subjects, we included only 939 subjects: those whose carotid ultrasound, analytical and anthropometric data were available. The reasons for the lack of data for the remaining 63 patients were as follows: 37 refused to undergo the echography, 14 withdrew from the study before conducting the test and 12 for other reasons [28].

\section{Metabolic phenotypes}

The different metabolic phenotypes included in the study were defined as follows: 1 . Metabolically healthy non-obese (MHNO): BMI $<30$ and $<2$ factors of cardiometabolic criteria. 2. Metabolically healthy obese (MHO): $\mathrm{BMI} \geq 30$ and $<2$ factors of cardiometabolic criteria. 3. Metabolically sick non-obese (MSNO): BMI $<30$ and $\geq 2$ factors of cardiometabolic criteria. 4. Metabolically sick obese (MSO): $\mathrm{BMI} \geq 30$ and $\geq 2$ factors of cardiometabolic criteria. Description of cardiometabolic disease criteria are in supplemental material. 


\section{Laboratory tests}

At $8.00 \mathrm{am}$, following a 12-h fast, the patients were admitted to the laboratory for anthropometric and biochemical tests [BMI, waist circumference, Waist to Height Ratio (WHTR), systolic blood pressure (SBP), diastolic blood pressure (DBP), HDL-cholesterol, LDLcholesterol, triglycerides, cholesterol, high sensitive Creactive protein (hsCRP), glucose, hemoglobin A1c (HbA1c) and homeostatic model assessment for insulin resistance (HOMA-IR)]as described in supplemental material.

\section{Intima media thickness assessment}

All the patients were examined in supine position with the neck hyper-extended and the chin turned to one side. The carotid arteries were examined bilaterally using a Doppler ultrasound high-resolution B-mode (Envisor C Ultrasound System, Phillips, USA), following the recommendations of the American Society of Echocardiography Carotid Intima-Media Thickness Task Force [27]. The observers were unaware of the patients' demographic and cardiovascular risk data during the assessment. The measurements were taken using semiautomatic software (QLAB Advance Ultrasound Quantification Software, v5.0, Phillips, USA). Three measurements were taken for each patient, and we obtained the general mean IMT-CC. Carotid atherosclerotic disease was defined by IMT-CC $\geq 0.7 \mathrm{~mm}[18,23]$. This cutoff value was used to calculate the prevalence of carotid atherosclerotic disease as a percentage of the patients with IMT-CC $\geq 0.7 \mathrm{~mm}$ from the total number of patients in each group analyzed.

\section{Statistical analysis}

The statistical analyses were carried out using SPSS version 19.0 for Windows (SPSS Inc., Chicago, IL, USA). Continuous data were compared by analysis of variance (ANOVA) in which smoking habit and sex were included as covariates. Categorical variables were compared using Chi Square tests. In order to assess the association between the phenotypes and the presence of carotid atherosclerotic disease, an odds ratios (OR) analysis was performed. Furthermore, backward multiple lineal and logistic analysis were carried out to estimate the association between cardiovascular risk factors and IMT-CC values. The differences were considered significant when $p<0.05$. All the data presented in figures and tables are expressed as means \pm standard error (SE).

\section{Results}

Study population characteristics based on age and metabolic phenotypes

In the analysis of the influence of age and metabolic phenotypes on biochemical and anthropometrics characteristics of the population (Shown in Supplemental Table 1), waist circumference and cholesterol showed a differential effect $(p<0.05)$ : MSO patients aged $<60$ years showed the highest waist circumference and MSNO and MSO patients aged $\geq 60$ years exhibited the lowest cholesterol. Furthermore, MSO patients aged $\geq 60$ years had higher insulin and HbA1c levels, but fewer BMI compared to those aged $<60$ years $(p<0.05)$; $\mathrm{MHO}$ patients aged $\geq 60$ years showed higher HDL-cholesterol levels compared to those aged $<60$ years $(p<0.05)$. In both age groups, MSO patients showed higher BMI, HOMA-IR, HbA1c and hsCRP levels compared to the rest of metabolic phenotypes (all $p<0.05$ ). However, only MSO patients aged $<60$ years showed higher waist circumference, glucose and insulin levels, and lower HDL-cholesterol levels, compared to the rest of metabolic phenotypes (all $p<0.05)$. In the analysis of WHTR, a biomarker of fat visceral deposit, age $>60$ years determined higher value than age $<60$ years, being all of them equal or upper 0.6 points which shows high risk of fat visceral localization with a subsequent loss in metabolic flexibility. In each group of age, we observed that in those age $>60$ years obesity determined higher WHTR than non-obese, however in age $<60$ years the highest value for this parameter belongs to those MSO.

\section{Differences in IMT-CC between metabolic phenotypes are influenced by age}

Regarding to the influence of metabolic phenotypes on IMT-CC, age resulted in a higher IMT-CC regardless of the metabolic phenotype (all $p<0.05$ ) (Fig. 1). In the group of patients aged $<60$ years, MHNO had the lowest IMT-CC compared to the other phenotypes $(\mathrm{p}<0.05)$. In the group of patients aged $\geq 60$ years, $\mathrm{MHNO}$ showed the lowest IMT-CC, while MSO patients presented the highest IMT-CC $(p<0.05)$, with intermediate values for IMT-CC in MHO and MSNO patients (Fig. 1).

\section{Age produces differences in the prevalence of carotid atherosclerotic disease according to metabolic phenotypes}

In order to find a link between the different metabolic phenotypes and the presence or not of carotid atherosclerotic disease, defined as IMT-CC $\geq 0.7 \mathrm{~mm}$, we calculated OR for both the whole study population and according to age. Table 1 shows the prevalence of carotid atherosclerotic disease and OR values. When we evaluated the whole population, the MHNO patients presented the lowest prevalence of carotid atherosclerotic disease compared to the rest of phenotypes. In patients aged $<60$ years, MHNO showed less prevalence of carotid atherosclerosis than MSNO and MSO phenotypes, but not MHO. However, in patients aged $\geq 60$ years, MHNO showed less prevalence of carotid 


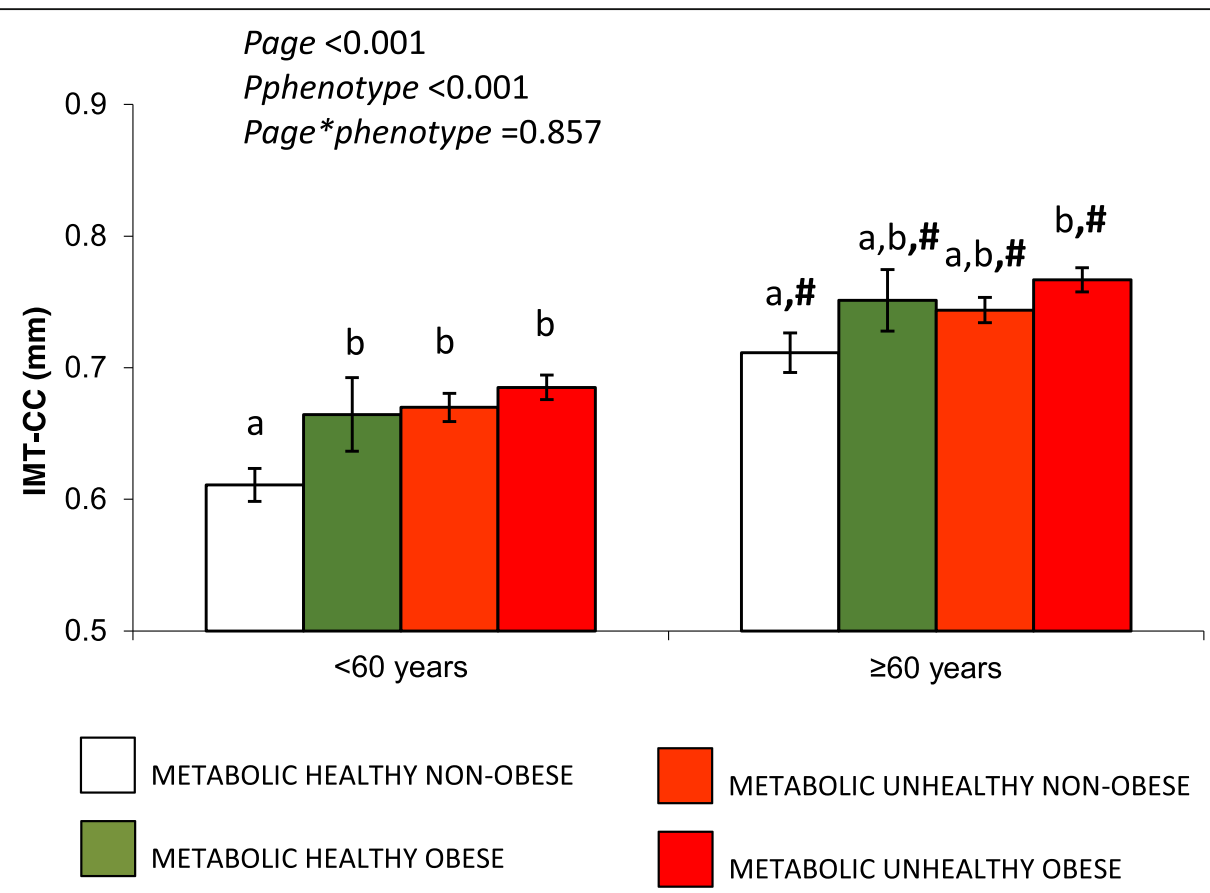

Fig. 1 Influence of metabolic phenotypes and age on IMT-CC. All data are mean $+/-$ SE. $p<.05$, Continuous variables were compared using the analysis of variance (ANOVA). \#p $<.05$ aged $<60$ years vs aged $\geq 60$ years. Bars with different letters a and $\mathrm{b}$ mean differences between metabolic phenotypes. IMT-CC: Intima media thickness-common carotid

atherosclerosis than MSO, but not less than the other phenotypes (Table 1).

Regarding to the OR analysis, we observed that in the whole population, MHO, MSNO and MSO phenotypes were associated with the presence of carotid atherosclerosis, taking the MHNO phenotype as a reference. In patients aged $<60$ years, the $\mathrm{MHO}$ phenotype was not associated with a higher prevalence of the disease compared to $\mathrm{MHNO}(\mathrm{OR}<1)$, but this association did appear with the presence of metabolic disease (OR = 2.42 for MSNO and 2.85 for MSO), although the value of prevalence of carotid atherosclerosis disease was seen to increase from MHNO to MSO. However, in the group of patients aged $\geq 60$ years, $\mathrm{MHO}$ and MSNO did not result in a higher probability of the disease than MHNO, while MSO showed an association with the presence of the disease [OR: 1.87 (1.02-3.42)].

\section{Multiple regression analysis}

In order to study which biochemical and anthropometric parameters $\mathrm{s}$ are involved in carotid atherosclerotic

Table 1 Prevalence of carotid atherosclerosis diseases according to metabolic phenotypes and its association study by Odds Ratios

\begin{tabular}{|c|c|c|c|c|c|}
\hline & MHNO & $\mathrm{MHO}$ & MSNO & MSO & $x^{2}$ Test \\
\hline All population $(n=939)$ & 109 & 71 & 305 & 454 & $p=0.003$ \\
\hline Carotid Atherosclerosis disease prevalence (IMT-CC $\geq 0.7 \mathrm{~mm}$ ) & $33.9 \%^{\mathrm{a}}$ & $49.3 \%^{\mathrm{b}}$ & $49.2 \%^{\mathrm{b}}$ & $54.0 \%{ }^{\mathrm{b}}$ & \\
\hline Odds Ratio & 1 & $1.89(1.03-3.49)$ & $1.88(1.19-2.97)$ & $2.28(1.47-3.53)$ & \\
\hline Age $<60(n=435)$ & 58 & 26 & 141 & 210 & $p=0.028$ \\
\hline Carotid Atherosclerosis disease prevalence (IMT-CC $\geq 0.7 \mathrm{~mm}$ ) & $19.0 \%^{\mathrm{a}}$ & $30.8 \%{ }^{a, b}$ & $36.2 \%^{\mathrm{b}}$ & $40.0 \%^{b}$ & \\
\hline Odds Ratio & 1 & $1.90(0.66-5.48)$ & $2.42(1.15-5.08)$ & $2.85(1.40-5.81)$ & \\
\hline Age $\geq 60(n=504)$ & 51 & 45 & 164 & 244 & $p=0.209$ \\
\hline Carotid Atherosclerosis disease prevalence (IMT-CC $\geq 0.7 \mathrm{~mm}$ ) & $51.0 \%^{\mathrm{a}}$ & $60.0 \% \%^{a, b}$ & $60.4 \%{ }^{a, b}$ & $66.0 \%{ }^{\mathrm{b}}$ & \\
\hline Odds Ratio & 1 & $1.44(0.64-3.24)$ & $1.46(0.78-2.75)$ & $1.87(1.02-3.42)$ & \\
\hline
\end{tabular}

Carotid Atherosclerosis disease (carotid intima media thickness $\geq 0.7 \mathrm{~mm}$ ) prevalence is expressed in percentage. Odds ratio values are calculated using MHNO phenotype as reference ( $95 \%$ confidence interval). Odds Ratio in bold mean that all values in the confidence interval are higher than $1 . x^{2}$ Test performed to compare prevalence of carotid atherosclerosis disease between metabolic phenotypes. Percentages in a row with superscripts with different letters a and $b$ mean differences between phenotype group 
disease among the different metabolic phenotypes, we performed a multiple logistic regression analysis (Table 2). In this regard, the presence of carotid atherosclerosis in the whole population seems to be associated with age, sex, IFG, hypertension and hsCRP. However, when we looked for these associations in each group split by age, we observed that in patients aged $<60$ years, carotid atherosclerosis was associated with sex and IFG, while in patients aged $\geq 60$ years, it appeared to be associated with hypertension and hsCRP.

\section{Discussion}

This study provides new findings about risk factors for carotid atherosclerosis associated with metabolic status and obesity, defined by metabolic phenotypes, and its relationship with age in patients with CHD. Our data highlights the age-dependency of this association and suggests that the relative importance of metabolic parameters and obesity differ in patients below and over 60 years old. Therefore, in patients aged $<60$ years, there is an increased risk of carotid atherosclerosis among the MSO, MSNO and MHO groups compared to MHNO, where IFG seems to be the most influential metabolic parameter. However, in patients aged $\geq 60$ years, those classified as MSO showed the highest risk for the disease, being hypertension, hsCRP and WHTR (a biomarker of fat visceral deposit) [24] the metabolic parameters that more contributed to the risk for carotid atherosclerosis. In the study of predictive and earlier biomarkers for CVD, IMT-CC is considered a surrogate marker that allows the anatomical changes in the arterial wall to be explored and quantified $[14,16]$ and can be used as an indicator of the presence of carotid atherosclerosis [5, 13]. Among risk factors studied regarding the development of carotid atherosclerotic disease, weight is considered an independent risk factor for CVD and is associated with higher mortality [1]. Obesity, and particularly central obesity, increases the risk of CVD and is associated with diabetes, hypertension and dyslipidemia, as well as other lifestyle risk factors such as physical inactivity and poor diet [20]. In this area, Choi et al. found that older MSNO adults showed a markedly higher risk of all-cause mortality, whereas overweight or obese subjects without metabolic disease had a comparatively lower risk of death [4].

The MHO phenotype has been described as an intermediate stage between a healthy and sick status, producing the same risk of suffering a cardiovascular event as MHNO [2]. Although this has been noted in most published studies, in the present study we observed a higher association with carotid atherosclerosis for the MHO phenotype than for MHNO. However, when we analyzed patients according to age, $\mathrm{MHO}$ patients aged $<60$ years showed no link to a higher prevalence of carotid

Table 2 Multiple logistic regression

\begin{tabular}{|c|c|c|c|c|c|}
\hline Variables & Coefficients & SE & $p$ & Odds Ratio & $95 \% \mathrm{Cl}$ \\
\hline \multicolumn{6}{|c|}{ The whole population } \\
\hline Age & 1.118 & 0.157 & 0.000 & 3.059 & $2.248-4.162$ \\
\hline Sex & 0.868 & 0.219 & 0.000 & 2.382 & $1.550-3.662$ \\
\hline IFG & 0.455 & 0.155 & 0.003 & 1.577 & $1.163-2.138$ \\
\hline hsCRP & 0.303 & 0.166 & 0.067 & 1.359 & $0.979-1.874$ \\
\hline Hypertension & 0.477 & 0.163 & 0.003 & 1.611 & $1.170-2.218$ \\
\hline WHTR & 1.897 & 1.135 & 0.095 & 6.666 & $0.720-61.672$ \\
\hline \multicolumn{6}{|c|}{ Patients Age $<60$ years } \\
\hline Sex & 0.849 & 0.414 & 0.041 & 2.337 & $1.037-5.264$ \\
\hline IFG & 0.836 & 0.228 & 0.000 & 2.308 & $1.478-3.605$ \\
\hline \multicolumn{6}{|c|}{ Patients Age $\geq 60$ years } \\
\hline Sex & 0.880 & 0.263 & 0.001 & 2.411 & $1.440-4.038$ \\
\hline Hypertension & 0.831 & 0.225 & 0.000 & 2.295 & $1.476-3.571$ \\
\hline hsCRP & 0.478 & 0.231 & 0.039 & 1.612 & $1.024-2.537$ \\
\hline WHTR & 2.830 & 1.526 & 0.064 & 16.940 & $0.850-337.420$ \\
\hline
\end{tabular}

$R^{2}=0.167$, constant $=-3.251(p=0.000)$. Alcohol consumption, smoking, LowHDL-c, HOMA-IR, HyperTG, Obesity and Waist Circumference have been eliminated from the model $(p>0.05)$

$R^{2}=0.072$, constant $=-1.859(p=0.000)$. Alcohol consumption, smoking, Obesity, LowHDL-c, HOMA-IR, HyperTG, Waist Circumference, Hypertension and hsCRP have been eliminated from the model $(p>0.05)$

$R^{2}=0.099$, constant $=-2.785(p=0.008)$. Alcohol consumption, smoking, Obesity, LowHDL-c, HOMA-IR, HyperTG, IFG and Waist Circumference have been eliminated from the model $(p>0.05)$

Multiple Logistic Regression with Age, Sex, IFG, LowHDL-c, hsCRP, HOMA-IR, Hypertension, Obesity, Waist Circumference, WHTR Waist to Height Ratio, HyperTG Alcohol consumption and Smoking as variable proved in the model. IFG Impaired Fasting Glucose, hsCRP high sensitive C-reactive protein, HOMA-IR homeostatic model assessment for insulin resistance, HyperTG Hypertrigliceridemia 
atherosclerosis. Moreover, the MSNO and MSO phenotypes showed a higher prevalence than MHNO. Indeed, an increasing prevalence of carotid atherosclerosis can be seen between MHNO and MSO.

Recent data from a 20-year follow up suggest that cumulative incidence rates for $\mathrm{CHD}$, stroke and survival probability in individuals with suboptimal health $(\leq$ two metabolic diseases factors) were intermediate between the healthy and unhealthy subgroups, which was not affected by the BMI [8]. In contrast to our results, accordance exists in the whole population and in patients aged $<60$ years, but not aged $\geq 60$ years, suggesting that, with the progression of age, there may be a loss in metabolic flexibility, where the presence of obesity could trigger, a loss in the capacity for lipogenesis with an increase of visceral fat depots coming from a dysfunctional adipose tissue, transforming the metabolically healthy obese in a phenotype associated with a higher risk for carotid atherosclerosis. In fact, the measure of fat visceral depots, through the WHTR, depicts how those age $\geq 60$ years had more than 0.6 which determines a high risk of fat visceral contributing to the development of metabolic inflexibility.

Hamer $\mathrm{M}$ et al. reported, in a stability study regarding the healthy obese phenotype, that unstable healthy obese (those who develop unhealthy status at the following 8 years) showed greater increases in central adiposity and impaired glycaemic control with slightly elevated levels of HbA1c [9]. In agreement with this study, in the multiple logistic regression analysis, we found that the impairment of glycaemic control, such as IFG, was associated with the presence of the disease, but only in patients aged $<60$ years. However, we showed that in those aged $\geq 60$ years, the association appeared for hypertension, increased hsCRP and WHTR. Here, therefore, our results showed up the evident different importance of these parameters in the high risk for carotid atherosclerosis observed among the metabolic phenotypes according to age. In a previous study from our group in this population, we demonstrated how certain types of the metabolic phenotypes are less favorable modulating phenotypic flexibility [19]. This fact suggests us that one of the mechanisms behind these effects, described above, could be related to the loss of capacity for lipogenesis with increasing adipose tissue and the gaining weight that occurs in adulthood. In those aged $<60$, these moderate changes in weight could be mitigated by maintaining these capacities which do not increase the numbers of risk factors. Surprisingly, smoking status (non-smoker, current smoker and ex-smoker) is kept out from all the models. Despite the fact that smoking is considered as an influential variable which is widely described in the literature, we must take into account the characteristics of our population, who are patients with CHD who have suffered a cardiovascular event, of which the percentage of active smokers is extremely low $(<10 \%)$ since they have all been previously recommended to give up smoking.

One of the limitations found in our study is that it is cross-sectional, which offers no evidence of causal effects, but instead provides a link between the diseases and the variables studied. On the other hand, this analysis could provide the basis for future approaches in longitudinal studies in order to clarify the influence of metabolic phenotypes in the development of carotid atherosclerosis and CVD measured by IMT-CC. In this context,

it is therefore important to identify the potential risk factors associated to the CVD risk and monitor them in the change from adulthood to old age. According to that, our study is focused on the analysis of this association, by assessing atherosclerotic disease, which is behind and preceding the development of cardiovascular events, so it could provide practitioners with information about their patients to act preventing the event or even mortality. It seems clear that high cardiovascular risk groups, such as $\mathrm{MHO}$ and, especially, those age $\geq 60$ years, would benefit from risk factor stratification to identify obese individuals who may gain most from modifying specific metabolic parameters, with the subsequent benefits for their metabolic health profile and a reduction in development of cardiometabolic disease.

\section{Conclusion}

In conclusion, our results suggest that in CHD patients, there is an age-dependent effect of metabolic phenotypes on carotid atherosclerotic disease. CHD patients aged $\geq 60$ years lose their metabolic flexibility compared to patients aged $<60$ years. This fact indicates the need to focus on therapeutic strategies in order to modify those parameters related to obesity and metabolic inflexibility in patients with CHD before entering old age.

\section{Supplementary information}

Supplementary information accompanies this paper at https://doi.org/10. 1186/s12877-020-01544-5.

\section{Additional file 1.}

\section{Abbreviations}

ANOVA: Analysis of Variance; BMI: Body Mass Index; CHD: Coronary Heart Disease; CVD: Cardiovascular Disease; DBP: Diastolic Blood Pressure; HbA1c: Hemoglobin A1c; HOMA-IR: Homeostatic Model Assessment for Insulin Resistance; hsCRP: High sensivity C-Reactive Protein; IFG: Impaired Fasting Glucose; IMT-CC: Intima Media Thickness-Common Carotid; MHNO: Metabolically Healthy non-Obese; MHO: Metabolically Healthy Obese; MSNO: Metabolically Sick non-Obese; MSO: Metabolically Sick Obese; O: Odds Ratio; SBP: Systolic Blood Pressure; SE: Standard Error; WHTR: Waist to Height Ratio 


\section{Acknowledgments}

We would like to thank the EASP (Escuela Andaluza de Salud Publica), Granada (Spain), for carrying out the randomization process in this study. The CIBEROBN is an initiative of the Instituto de Salud Carlos III, Madrid, Spain.

\section{Authors' contributions}

FMG-M, EMY-S, and JL-M: designed the study hypothesis, analyzed the data, and wrote the manuscript; EMY-S and JL-M: had primary responsibility for the final content of the manuscript; JD-L, PP-M, AL-A and RML: contributed to the editing of the manuscript; FMG-M, AG-R, PG-L, CF-G, MPC, SdIC-A and FR-C: conducted the research; AL-A and JD-L: provided the statistical review; PP-M and RM-L: contributed to the interpretation of data and substantively revised the manuscript; JL-M and EMY-S: designed the research and supervised the study; and all authors read and approved the final manuscript. None of the authors reported a conflict of interest related to the study.

\section{Funding}

The CORDIOPREV study is supported by the Fundacion Patrimonio Comunal Olivarero, Junta de Andalucia (Consejeria de Salud, Consejeria de Agricultura y Pesca, Consejeria de Innovacion, Ciencia y Empresa), Diputaciones de Jaen y Cordoba, Centro de Excelencia en Investigacion sobre Aceite de Oliva y Salud and Ministerio de Medio Ambiente, Medio Rural y Marino, Gobierno de España. The CORDIOPREV study also received research grants from Consejeria de Salud, Junta de Andalucia (PI0193/09 to Dr. Lopez-Miranda, PI0252/09 to Dr. Delgado-Lista, and PI-0058/10 to Dr. Perez-Martinez); Proyecto de Excelencia, Consejería de Economía, Innovación, Ciencia y Empleo (CVI7450 to Dr. Lopez-Miranda); and from the Ministerio de Economia y Competitividad (AGL2012-39615 and AGL2015-67896-P to Dr. Lopez-Miranda integrated into the framework of the National Plan for Scientific Research, Technological Development and Innovation 2008-2011 and 2013-2016, cofinanced by the Instituto de Salud Carlos III (ISCIII) of Spain and also by the Directorate General for Assessment and Promotion of Research and the EU's European Regional Development Fund (FEDER). It was also partly supported by a Research Grant from the European Community (NUTRITECH European Integrated Project-289511). Dr. Gutiérrez Mariscal is supported by a research contract from the University of Cordoba (Plan Propio de Investigación UCO 2017). The CIBEROBN is an initiative of the ISCIII. The contents of this paper are not intended for any commercial use. Funders did not have any role in the design of the study and collection, analysis, and interpretation of data and in writing the manuscript.

\section{Availability of data and materials}

The datasets used and/or analyzed during the current study are available from the corresponding author on reasonable request.

\section{Ethics approval and consent to participate}

The study protocol was designed in accordance with the principles of the Declaration of Helsinki, approved by the Human Investigation Review Committee of the Reina Sofia University Hospital, and according to institutional and Good Clinical Practice guidelines. The participant informed written consent was submitted to the Ethics Committee.

\section{Consent for publication}

Not applicable.

\section{Competing interests}

The authors declare that they have no competing interests.

\section{Author details}

${ }^{1}$ Lipids and Atherosclerosis Research Unit, Avda. Menéndez Pidal, s/n, Reina Sofia University Hospital, Maimonides Institute for Biomedical Research in Cordoba (IMIBIC), University of Córdoba, 14004 Córdoba, Spain. ${ }^{2}$ CIBER Physiopathology of Obesity and Nutrition (CIBEROBN), Carlos III Health Institute, Madrid, Spain. ${ }^{3}$ Biochemical Laboratory, Reina Sofia University Hospital, Córdoba, Spain. ${ }^{4}$ Department of Cell Biology, Physiology and Immunology, Maimonides Institute for Biomedical Research in Cordoba (IMIBIC), University of Córdoba, Reina Sofia University Hospital, Córdoba, Spain.
Received: 7 October 2019 Accepted: 1 April 2020

Published online: 22 April 2020

\section{References}

1. Aparicio HJ, et al. Overweight, obesity, and survival after stroke in the framingham heart study. J Am Heart Assoc. 2017;6:e004721.

2. Arnlov J, Sundstrom J, Ingelsson E, Lind L. Impact of BMI and the metabolic syndrome on the risk of diabetes in middle-aged men Diabetes care. Diabetes Care. 2011;34:61-5.

3. Bradshaw PT, Monda KL, Stevens J. Metabolic syndrome in healthy obese, overweight, and normal weight individuals: the atherosclerosis risk in communities study. Obesity (Silver Spring). 2013;21:203-9.

4. Choi KM, et al. Higher mortality in metabolically obese normal-weight people than in metabolically healthy obese subjects in elderly Koreans. Clin Endocrinol. 2013;79:364-70.

5. Coll B, Betriu A, Feinstein SB, Valdivielso JM, Zamorano JL, Fernandez E. The role of carotid ultrasound in assessing carotid atherosclerosis in individuals at low-to-intermediate cardiovascular risk. Rev Esp Cardiol (Engl Ed). 2013;66: 929-34. https://doi.org/10.1016/j.rec.2013.05.030.

6. Delgado-Lista J, et al. CORonary Diet Intervention with Olive oil and cardiovascular PREVention study (the CORDIOPREV study): Rationale, methods, and baseline characteristics: A clinical trial comparing the efficacy of a Mediterranean diet rich in olive oil versus a low-fat diet on cardiovascular disease in coronary patients. Am Heart J. 2016;177:42-50. https://doi.org/10.1016/j.ahj.2016.04.011.

7. Flegal KM, Kruszon-Moran D, Carroll MD, Fryar CD, Ogden CL. Trends in obesity among adults in the United States, 2005 to 2014. JAMA. 2016;315: 2284-91. https://doi.org/10.1001/jama.2016.6458.

8. Guo F, Garvey WT. Cardiometabolic disease risk in metabolically healthy and unhealthy obesity: stability of metabolic health status in adults. Obesity (Silver Spring). 2016;24:516-25.

9. Hamer M, Bell JA, Sabia S, Batty GD, Kivimaki M. Stability of metabolically healthy obesity over 8 years: the English longitudinal study of ageing. Eur J Endocrinol. 2015;173:703-8.

10. Karelis AD. To be obese--does it matter if you are metabolically healthy? Nat Rev Endocrinol. 2011;7:699-700. https://doi.org/10.1038/nrendo.2011.181.

11. Karelis AD, Faraj M, Bastard JP, St-Pierre DH, Brochu M, Prud'homme D, Rabasa-Lhoret R. The metabolically healthy but obese individual presents a favorable inflammation profile. J Clin Endocrinol Metab. 2005;90:4145-50. https://doi.org/10.1210/jc.2005-0482.

12. Karelis AD, St-Pierre DH, Conus F, Rabasa-Lhoret R, Poehlman ET. Metabolic and body composition factors in subgroups of obesity: what do we know? J Clin Endocrinol Metab. 2004;89:2569-75. https://doi.org/10.1210/jc.20040165.

13. Kim HN, Kim SH, Eun YM, Song SW. Obesity with metabolic abnormality is associated with the presence of carotid atherosclerosis in Korean men: a cross-sectional study. Diabetol Metabol Syndrome. 2015;7:68.

14. Kim HS, Cho Kl. Association of carotid artery parameters of atherosclerosis in coronary artery disease. J Cardiovasc Ultrasound. 2013;21:72-80. https://doi. org/10.4250/jcu.2013.21.2.72.

15. Lopez-Miranda J, Perez-Martinez P. It is time to define metabolically obese but normal-weight (MONW) individuals. Clin Endocrinol (Oxf). 2013;79:3145. https://doi.org/10.1111/cen.12181.

16. Lorenz MW, Markus HS, Bots ML, Rosvall M, Sitzer M. Prediction of clinical cardiovascular events with carotid intima-media thickness: a systematic review and meta-analysis. Circulation. 2007;115:459-67. https://doi.org/10. 1161/CIRCULATIONAHA.106.628875.

17. Morkedal B, Vatten LJ, Romundstad PR, Laugsand LE, Janszky I. Risk of myocardial infarction and heart failure among metabolically healthy but obese individuals: HUNT (Nord-Trondelag health study), Norway. J Am Coll Cardiol. 2014;63:1071-8.

18. O'Leary DH, Bots ML. Imaging of atherosclerosis: carotid intima-media thickness. Eur Heart J. 2010;31:1682-9. https://doi.org/10.1093/eurheartj/ ehq185.

19. Perez-Martinez $\mathrm{P}$, et al. Metabolic phenotypes of obesity influence triglyceride and inflammation homoeostasis. Eur J Clin Invest. 2014;44:105364. https://doi.org/10.1111/eci.12339.

20. Perez-Martinez $P$, et al. Lifestyle recommendations for the prevention and management of metabolic syndrome: an international panel recommendation. Nutr Rev. 2017;75:307-26. https://doi.org/10.1093/nutrit/ nux014. 
21. Pischon T, et al. General and abdominal adiposity and risk of death in Europe. N Engl J Med. 2008;359:2105-20. https://doi.org/10.1056/ NEJMoa0801891.

22. Rescigno T, Micolucci L, Tecce MF, Capasso A. Bioactive nutrients and nutrigenomics in age-related diseases. Molecules. 2017;22:E105. https://doi. org/10.3390/molecules22010105.

23. Rohde LE, et al. Circulating cell adhesion molecules are correlated with ultrasound-based assessment of carotid atherosclerosis. Arterioscler Thromb Vasc Biol. 1998;18:1765-70

24. Shen SW, et al. Waist-to-height ratio is an effective indicator for comprehensive cardiovascular health. Sci Rep. 2017;7:1-7. https://doi.org/10. 1038/srep43046

25. Sniderman AD, Furberg CD. Age as a modifiable risk factor for cardiovascular disease. Lancet. 2008;371:1547-9.

26. Song Y, Manson JE, Meigs JB, Ridker PM, Buring JE, Liu S. Comparison of usefulness of body mass index versus metabolic risk factors in predicting 10-year risk of cardiovascular events in women. Am J Cardiol. 2007;100: 1654-8. https://doi.org/10.1016/j.amjcard.2007.06.073.

27. Stein $\mathrm{JH}$, et al. Use of carotid ultrasound to identify subclinical vascular disease and evaluate cardiovascular disease risk: a consensus statement from the American Society of Echocardiography carotid intima-media thickness task force. Endorsed by the Society for Vascular Medicine. J Am Soc Echocardiogr. 2008;21:93-111; quiz 189-190. https://doi.org/10.1016/j. echo.2007.11.011.

28. Talavera-Garcia E, et al. Influence of obesity and metabolic disease on carotid atherosclerosis in patients with coronary artery disease (CordioPrev study). PLoS one. 2016;11:e0153096. https://doi.org/10.1371/journal.pone. 0153096.

29. Twells LK, Gregory DM, Reddigan J, Midodzi WK. Current and predicted prevalence of obesity in Canada: a trend analysis. CMAJ Open. 2014;2:E1826. https://doi.org/10.9778/cmajo.20130016.

30. Weinert BT, Timiras PS. Invited review: theories of aging. J Appl Physiol. 2003;95:1706-16. https://doi.org/10.1152/japplphysiol.00288.2003.

31. Zhang C, Rexrode KM, van Dam RM, Li TY, Hu FB. Abdominal obesity and the risk of all-cause, cardiovascular, and cancer mortality: sixteen years of follow-up in US women. Circulation. 2008;117:1658-67. https://doi.org/10. 1161/CIRCULATIONAHA.107.739714.

\section{Publisher's Note}

Springer Nature remains neutral with regard to jurisdictional claims in published maps and institutional affiliations.

Ready to submit your research? Choose BMC and benefit from:

- fast, convenient online submission

- thorough peer review by experienced researchers in your field

- rapid publication on acceptance

- support for research data, including large and complex data types

- gold Open Access which fosters wider collaboration and increased citations

- maximum visibility for your research: over $100 \mathrm{M}$ website views per year

At $\mathrm{BMC}$, research is always in progress.

Learn more biomedcentral.com/submissions 